\title{
Euthanasia: In Defense of A Good, Ancient Word
}

Dragan Pavlovic $^{1 *}$, Alexander Spassov ${ }^{2}$ and Christian Lehmann ${ }^{3}$

${ }^{1}$ Department of Anesthesia and Intensive Care Medicine, Ernst Moritz Arndt University, Germany

${ }^{2}$ Department of Orthodontics, Faculty of Medicine, University of Greifswald, Germany

${ }^{3}$ Department of Anesthesia and Intensive Care Medicine, Ernst Moritz Arndt University, Germany

\section{Abstract}

Background: It has been suggested that the word euthanasia should be abandoned because widespread imprecise use of the word "euthanasia" deprived it of its precise meaning.

Methods: On the basis of the primary necessary condition for euthanasia - that it be in the interests of the one who will die - we examine the use and meaning of the expression.

Discussion: We demonstrate that above suggestions rely upon flagrant misuse or inappropriate use of the word. The attention of the reader is drawn to morally problematic consequences should the expression "euthanasia" be abandoned and the argument that abandoning the term would be justified is rejected.

Conclusions: Instead of abandoning the word "euthanasia," care should be taken to use the term correctly in the future. The original meaning of the word "euthanasia" would, thereby, be preserved and we could only benefit from the rich tradition that impregnates that ancient word.

Keywords: Euthanasia; Animal experimentation; Terminal care; End-of-life

\section{Background}

\section{Condemned words}

Words, like living creatures, do not last forever and may fall into oblivion or literally disappear. There are, for example, a number of ancient Greek words for which we can barely reconstruct meanings after they have fallen out of use for such a long time (alexiteric, for example, once used as an adjective to describe a preservative or protective agent against contagion, infectious disease, or poison). Some words, such as politically incorrect words which are intended to express racist feelings, may actively be removed from use. These politically incorrect, condemned words tend to disappear almost spontaneously after they have been publicly denigrated; or they may even be removed through legislation (for example, use of any pejorative racial epithet to indicate a "black person"). There are other words that are out of use because their objects of reference have disappeared. These words remain as an intellectual inheritance in history books or other resources. We no longer measure length in stadia as Greeks used to do. Or ostracism is a word not employed any more for removing politicians who gained too much popularity - nobody is ostracized in that sense today. Indeed, in the last century it was still possible to force political opponents into exile, which was more or less similar to ostracism although not identical. We may still use these words metaphorically, however.

Our subject here is euthanasia, a word that is almost as old as human civilization and has been used up until our era to mean a good, easy, pleasant death for someone who must die. Nowadays, suggestions are being made, in particular in Germany [1] that its use should be discontinued in the future since it is vague [1-5] and, additionally, has been abused in the past [1]. Whether this can be justified is the subject of this short text. We shall claim that the use of the word "euthanasia" should be restricted and should include neither Nazi practices nor animal killing in scientific experiments.

At the center of the essay that follows will be the word, "euthanasia," that stands for the concept of "a good death." The essay will discuss why and how this word should not be, as some presently urge, abandoned
[1-5]. Through our discussion, we ask the reader to keep in mind the concept of "a good death." Importantly, for the sake of the terminally ill patients who often desperately need this concept, practicing physicians in intensive care units (ICU) and other medical settings where such patients are treated also require it. Positively, the notion of "a good death" must be retained in order to permit the expression of free will and respect for the dignity of the patient as an independent human being. On the other hand, both the word "euthanasia" and the concept of "a good death" must be well protected from inappropriate and careless use. The word "euthanasia" certainly should not be discarded. As we shall see, if we gave way to this suggestion, we would be incorrectly acting under the sway of inappropriate usage. While it is claimed that abandoning the word should be done in order to "preserve" the concept, the reality is exactly the opposite: abandoning the word "euthanasia" necessarily jeopardizes the very concept of "a good death".

\section{Methods}

To be able to advance further we need some acceptable definition of euthanasia. Admittedly, defining euthanasia is indeed hard. Often it would be satisfactory to say that it is "the act or practice of killing or permitting the death of hopelessly sick or injured individuals (as persons or domestic animals) in a relatively painless way for reasons of mercy" (Merriam-Webster Online Dictionary, http://www.merriamwebster.com/dictionary/euthanasia, accessed July $\left.1^{\text {st }}, 2010\right)$. Most medical dictionaries would refer to euthanasia as the intentional killing by act or omission of a dependent human being for his or her alleged

*Corresponding author: Dr.Dragan Pavlovic, Klinik und Poliklinik fü Anästhesiologie und Intensivmedizin, Ernst-Moritz-Arndt Universität, FriedrichLoeffler-Strasse 23b, 17487 Greifswald, Germany, Tel: 49383486 5848; Fax: 49 383486 80104; E-mail: pavlovic@uni-greifswald.de

Received November 25, 2010; Accepted December 23, 2010; Published January 03, 2011

Citation: Pavlovic D, Spassov A, Lehmann C (2011) Euthanasia: In Defense of A Good, Ancient Word. J Clinic Res Bioeth 2:105. doi:10.4172/2155-9627.1000105

Copyright: (c) 2011 Pavlovic D, et al. This is an open-access article distributed under the terms of the Creative Commons Attribution License, which permits unrestricted use, distribution, and reproduction in any medium, provided the original author and source are credited. 
benefit. Indeed, it is notoriously difficult to produce a definition that would exclude misunderstandings or even misuses [6].

We now introduce two premises which will serve us later to evaluate two moral positions that are central to the present discussion about the term euthanasia (in the further text we italicise the word "euthanasia" irrespective of whether it refers to the term or to the act, and we hope that this will be clear from the context). (A) for our purpose here, one of the essential meanings (necessary condition) of "euthanasia" will be used, as defined by Beauchamp and Davidson [6]: "euthanasia" is an act which fulfils the interests of one who will die" (will be referred to later as B/D). (B) Also, we will assume the intention (INT) of the actor to be a necessary, but not sufficient, condition of a moral action. For example such an action could be euthanasia if it were done with an intention to save from suffering somebody who explicitly expressed such a desire [7]. To restrict the meaning of the word "euthanasia" will require that we concentrate not so much on what the meaning of the word is, but more on what that meaning is not or, according to our position, should not be.

\section{The problem: Two moral positions}

There are two points of view (we will call them moral positions later) that can be found in medical literature in relation to the expression "euthanasia", both of which appear to reinforce and are greatly interdependent on one another. First is that the word euthanasia was abused and therefore should not be used any more. The second is that the word euthanasia is used for acts which are not euthanasia (in animal experimentation), and that therefore the word should not be used any more to describe the act that originally was euthanasia. If accepted, these arguments may lead to abandoning the word "euthanasia" for the cases for which it has currently been used. However, it will be important to preserve the word, not only because of the high cultural value of the word "euthanasia", but also, because actively avoiding to use the word may potentially legitimize its abuse. Therefore, we will try to prove that both above mentioned moral positions are wrong. If we succeed in our enterprise, the danger that the ancient word will be abandoned would be removed.

The first of the two moral positions is that we should stop using the word "euthanasia" because it was flagrantly abused by the Nazis and has therefore lost its original meaning [1]. It is sometimes maintained that further remodeling of our intellectual tradition is needed to help increase our moral awareness related to memory of crimes against humanity. Indeed, the Nazis did use utterly false excuses to justify killing innocent people for political or racist purposes. The German Federal Archive in Berlin has gathered information from almost 300 archives in Germany, Austria, Poland, and the former Czechoslovakia and in 2003, for the first time, files relating to the 200.000 euthanasia crimes of the Nazi regime from 1939 to 1944 were made available online in a central databank [8].

During the "euthanasia" program, the victims received various kinds of terminal treatment. The law about "euthanasia" dated from 14 July, 1933, but the Euthanasieprogramm started in fact after Poland was occupied, when on September 1, 1939, one child was "euthanized", after Hitler had personally issued a permit [9]. The acts of "euthanasia" were "justified" by patients' irreversible states of illness, including mental or physical disorders, as well as by unrelated external factors, including economic or broader social criteria, such as burden to relatives, subjective and wrong judgments about patients' quality of life, etc. These were not in accordance with B/D and consequently, the meaning of "euthanasia" was, thereby, abusively extended.
Very much linked to this is the second moral position referring to one modern use of the word "euthanasia". It is a quite widespread practice to describe the killing of an animal at the end of medical experimentation as "euthanasia" [10-13]. The typical expression is, for example: "After the experiment, the animals were euthanized by injecting an overdose of pentobarbital." It is claimed that this is in accordance with $\mathrm{B} / \mathrm{D}$.

It is undisputed that, in the light of the above mentioned $\mathrm{B} / \mathrm{D}$ clause, the Nazi "euthanasia" program was an abuse of the word "euthanasia". It is, on the other hand, not so obvious whether accepting the second position and use of the word "euthanasia" for "mercy" killing of animals at the end of experimentation is also in contradiction with the $\mathrm{B} / \mathrm{D}$ clause. We will deal with the latter first.

\section{Discussion}

\section{Second moral position refuted}

If we look deeper into the problem a different picture appears. Why should not the act we perform at the end of an animal experiment be termed "euthanasia"? This is simply because one cannot, for example, induce experimental sepsis in an animal, cut its abdomen and very probably infects it mortally, and then, when the experiment is finished, kill the animal and claim to be performing "euthanasia" simply because a reasonable life would no longer be possible for the animal. This sounds strange. Indeed, the isolated act of terminating the life of an animal which can not continue normal, valuable life after our experiment, according to the above given definition could be "euthanasia". However, to decide what kind of an act this is, the entire procedure must be seen as a whole. Indeed, to decide whether a fragment of an act is euthanasia or not, the entire act and the intentions (INT) behind the act must be taken into account. Particularly useful here could be the matching rule, that has been used in developmental studies in children, and which specifies that if there is a match between an intentional state and behavioural outcome then the outcome is intended [14]. We may apply the rule here only to quantify how much in fact the mercy killing was contained in the intention that preceded a given animal experimentation. To avoid the difficulty that would arise if we would try to define time frames after the start of a single intentional act, we propose that we should be satisfied with the fact that the act of killing follows closely and is a kind of a "product" of another act - an experiment - which is not in the interests of an animal and therefore the act of killing an animal can not be euthanasia.

The intention that dominates each animal experiment is almost never in the interest of an animal and the wish to diminish pain of the mutilated animal is a "product" of that original intention. The final act of killing an animal would be morally justifiable only in the light of the original act - only if the previous act could be justified, could the subsequent act also be justified. However, the intention behind animal experimentation can not make the outcome become "euthanasia" because it is certainly not done in the interests of the animal, i.e., it is not in accordance with $\mathrm{B} / \mathrm{D}$. The animal is brought into such a state not for its own benefit, but to satisfy other, external interests, such as to acquire some scientific knowledge and to find, for example, a cure for diseases; all for our human benefit. So this could not be "euthanasia".

The abuse of the term can be further illustrated with two other related examples from our world today; the death penalty or executions in war. When, during a war, somebody is executed (this designating INT), but appears to still be alive, and an executioner comes at close range and fires a bullet in the victim's head, what is the intention of the act? Is this "euthanasia"? Certainly not. Or, after the unsuccessful first 
administration of the deadly injection during the execution of capital punishment (which is, again, designating INT), a second injection is given which terminates the prisoner's life - is this last act "euthanasia"? Were people in the Nazi concentration camps, which were killed after being starved to skin and bones, "euthanized"? Again, the intention (INT) was not to assure pleasant death, but to exterminate "lower" people. Therefore, this was not "euthanasia". However, and this is an important point, if one permits the abuse of the term in the case of animal experimentation, thereby redefining the term, then these above described acts would also be "euthanasia", and this is absurd.

An argument could be advanced that what is done in animal experimentation, is all done for science and science is valuable. Science is, of course, not done for the good of the ones (animals) who die for science, although some animals will profit from science. Indeed, examples of a different sort of "euthanasia" on animals can be found and are, in fact, quite frequent: when a master/mistress submits to the "euthanation" of her/his beloved pet which is too old and too sick to continue its pet life normally and to free it from terrible suffering. But this is not the same as the case of the experimental animals.

\section{Interdependence and consequences}

Let us now return to the first moral position. If the first position is acceptable, i.e., if the word "euthanasia" no longer means what it used to mean before its abuse, precisely because that abuse took place, then we need another expression to describe the act of terminal care for patients. Let us say, for this occasion we will call it "help by dying". If one accepts adopting some other, "better expression" to describe the terminal care of patients, this would deprive the word "euthanasia" of its original meaning. Indeed it may lead even to the uses of the word for the cases like animal mercy killing or for the extreme examples like Nazi crimes. Therefore, it would be possible to use the word euthanasia for acts not in the interests of one who will die. Thereby the abusive meaning would become its true meaning.

Pushed to the extreme, then, this would mean that what the Nazis did could be described today as "euthanasia", since today's description of the act of helping someone to die (passive or active "euthanasia") would be described in other, supposedly more adequate, terms ("help by dying"). Replacing today the word "euthanasia" by these or some other supposedly more adequate words would imply that the Nazi use was, in fact, an abuse at that time, while it could (and by that very act would) become its correct use today.

On the other hand, if the second position were acceptable, it would be acceptable to say, "after performing experiments, animals are 'euthanized"', making the first position, likewise, acceptable. By approving the use of the word in the second sense (and denying the clause $B / D$ ), we accept the redefinition of the word "euthanasia" and include such cases as the killing of animals not for the animals' interests, but for other interests, i.e. scientific interests. The principles that would be applied then would be, it appears, not much different from the principles that the Nazis applied to perform the so-called "euthanasia" program (also denying the $\mathrm{B} / \mathrm{D}$ ). The consequence would be that the concept does not match present reality, and that one should stop using the word "euthanasia" when describing what is carried out on patients. Instead of the word euthanasia, it is claimed, it is necessary to propose another, more precise, expression.

\section{Vagueness}

One reason given for abandoning the expression "euthanasia" is its vagueness [1-5]. Indeed, the ancient word always had a very general meaning, impossible to define precisely, although it always assumed that the person who would die had made the decision himself and that the act had a suicidal component. Hippocrates, as could be seen from the Hippocratic Oath (although it may not have been written by him), forbade a physician from performing anything like terminal assistance. Socrates, on the other hand, at the turn of the $5^{\text {th }}$ century BC does not seriously oppose his execution. Later, $4^{\text {th }}$ century Greek philosophy is, however, hostile towards suicide. Aristotle insists that suicide is by itself abnormal and unjust, and is therefore forbidden by law; it is even, according to him, to be considered a cowardly act [15]. A number of biographers of Alexander III of Macedonia (the Great), describe in about $325 \mathrm{BC}$ the voluntary death of an old and sick Indian wise man, Calanus, who followed Alexander [16-19]. The king greatly honored Calanus' decision, although as a student of Aristotle probably not approving of it, and arranged for a spectacular, solemn event. Certainly, this was not the first encounter of the Macedonians or the Greeks with the heroic, good death; known at least as early as Homeric times.

The word "euthanasia", however, was not used by these authors but the concept undoubtedly existed. Later, according to the Henri Estienne?s Thesaurus Graecae linguae [20], a number of Greek authors

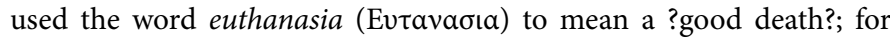
example Cratinus ( $5^{\text {th }}$ century BC), Menander of Athens (342-291), Philon the Jew (280-220), or Polybius (190-85). Later, Romans also highly praised "euthanasia". Cicero (106-43) [21] or, later, Suetonius (70-140) [22], used it when writing about the death of Emperor Octavian August, who himself, according to Suetonius, even defined "that Greek word" to describe an "easy, painless, good death that follows a successful life". In the present text we have restricted the meaning of "euthanasia" according to Beauchamp and Davidson [6] which reflects the modern concept extending far beyond suicide, since the action (or inaction, as in the passive forms that allow a patient to die) is also used in reference to another person who, according to the explicit or presumed wishes/interests of the person who chooses to die or will die, will carry out those wishes. This, however, introduced a dangerous slippery slope which may have been the origin of the second moral position, introduced at the beginning of our text. Unfortunately, sometimes the interests or wishes of the one who will die can not be determined. We have argued elsewhere that in such cases, then the emotional concerns of other people may offer guidance for such decisions [23]. This may be used only when deciding whether or not to prolong life and certainly not when deciding whether or not to terminate life, for which these presumed wishes or interests would be necessary but not sufficient.

The problem of the vagueness of words has been extensively discussed in the past. A project that has been abandoned as unfeasible was that the philosophical problems would be resolved as soon as language usage would be made more accurate. This led to a particularly dramatic failure of efforts of logical positivism and of the "philosophy of language» as clearly declared by R. Rorty, one of the early partisans of that otherwise very fruitful current [24].

It became evident that a single word does not exist which could describe a complex notion without redundancy; or which, if encompassing exhaustively the meaning, would not, at the same time, be vague. The contrary would also apply: the more precise a definition, the more it loses content and the less useful it is. The biological scientists are often well accustomed to the sensitivity and specificity dichotomy that is analogous with the above described problem: the more some test (i.e., definition) is specific, the smaller its range will be, although the number of false negative results (items that the definition or the test do not include) will be increased; or the more sensitive it is, the less 
well defined would be its limits and more false positive results would be obtained. Even if a better expression were to be introduced, the problems one periodically has in defining various facets of "euthanasia", along with the need to introduce a comprehensive list of terms that would describe these facets in practice, would most likely remain. This being so, the solution is to keep "euthanasia" as vague as it already is, while maintaining the need for defining its numerous aspects.

Certainly, words have been abused in the past and will be abused in the future. Words like love, justice, democracy, socialism, nation, even God, are no exceptions, and have even been used and abused to promote terrible crimes. We think that not to use or even to forbid the use of the word "euthanasia" would be an enormous error. Those making the proposal are probably not conscious of the fact that, over 60 years after the last Nazi victim succumbed, their plea would lead to yet another victim of Nazi ideology: good old word "euthanasia". Yet, National-Socialists abused the expression "German people" (Deutsches Volk); Nazi propaganda declared that all that was done was in the name of the Deutsches Volk. It will probably take a long time before this expression regains its full, original meaning. Jugend and Genosse are words whose meaning still carries unpleasant connotations. Even the German language was abused. Should the German language be forbidden? This is, of course, a gross absurdity.

\section{Two possible objections}

One objection to our proposal may be that we must first discuss the assumption that the word "euthanasia" has changed its original meaning to such an extent that its use in animal experimentation today could be consistent with that changed meaning. Our response to this follows along the lines of what we said above.

a. There is no doubt that today "euthanasia" means what philosophers of ethics put forth as repeatedly cited above. The most significant modern experts in the field have also been referenced, and it is very clear indeed what the word means and when it should be used.

b. Furthermore, if some experimental biologists would start (as some in fact do) using the word "euthanasia" incorrectly, extending its meaning (certainly unconsciously) along those lines of Nazi ideology, and would insist that the word changes its meaning, we should explain to them:

1. That such use is incorrect.

2. That the meaning of the word is by no means to be changed because such a change may and will produce a kind of double effect: perhaps unpleasant connotations related to its misuse will disappear, but unwontedly, it may happen that such employment of the word will encourage or support in one way or another the Nazi usage signifying acts which were inhuman and unethical.

The other objection to our proposal could be that one has to take history into consideration and this may demand "sacrifices". We agree with this. Let us, rather, sacrifice that particular meaning of "euthanasia" which would be: "killing somebody/some creature NOT only in her/ his/its interests".

\section{Conclusions}

Our position is, then, that the Nazi Program should not be termed "euthanasia"; and, related to this issue, that the usage of the word "euthanasia" to describe the killing of animals at the end of biological experimentation should be abandoned. Instead expressions such as: para-euthanasia (suggesting changed meaning), pseudo-euthanasia (suggesting not true euthanasia), tachy-euthanasia (accelerated death), or, simply, induced death would be more appropriate for animal experiments (as suggested by Dr. M. Vulic, personal communication). The consequences of the article should be that the Nazi Euthanasia program should not, be described as a "euthanasia" program after all - after it has been definitely condemned as a terrible crime. Indeed, it is of particular interests in Germany not to avoid the use of the word "euthanasia", and instead to insist on its correct use. This may be a way to avoid possible accusations of silently offering a new victim to the Nazi ideology and of supporting the neo-Nazi intention to apologize for the murderous acts by describing them as "euthanasia". However, by preserving the word we may save the very essence of the term "euthanasia" and we would only profit from the rich tradition that impregnates that ancient word.

Indeed, more profound analysis, as we demonstrated, indicates that a correction of the mentioned misconception about the word euthanasia would: (i) be beneficial to our further refutation of Nazi ideology and increase our moral awareness for contemporary events, and, (ii) extend our moral concerns to cover, in addition, animal care. Morality is one of the components of our well-being and by increasing moral awareness in general, new valuable perspectives for humanity may be made possible.

\section{Appendix}

\section{Competing Interests}

The authors declare that they have no competing interests.

\section{Authors' Contributions}

DP initiated the project and wrote the manuscript. ChL and AS discussed initially the project, read and corrected various versions of the manuscript and helped develop arguments.

\section{About the Authors}

DP (MD) is Research Director at the Department of Anesthesiology and Intensive Care Medicine at the University of Greifswald, Germany. His interest is focused on fundamental muscle research related to circulation in experimental sepsis and asthma as well as medical ethics, philosophy of science and scientific method.

ChL (MD) was Professor of Anesthesiology at the Department of Anesthesiology and Intensive Care Medicine at the University of Greifswald, Germany. Presently, he is in the Department of Anesthesia, Dalhousie University, Victoria General Hospital 1278 Tower Road, 10 West, Halifax B3H 2Y9, Canada, e-mail: chlehmann@mac. com. His main interest is clinical and basic sepsis research, mainly centered on microcirculation. He is also interested in ethical issues related to the end-of-life care.

AS (Dr. of Dentistry), is Senior Instructor in Dentistry, at the Department of Orthodontics, Faculty of Medicine, University of Greifswald, Germany. His interests focus on masticatory muscle research and biomedical ethics applied to dentistry.

\section{References}

1. Michalsen A, Reinhart K (2006) "Euthanasia": A confusing term, abused unde the Nazi regime and misused in present end-of-life debate. Intensive Care Med 32: $1304-1310$

2. Kuiper AM, Whetstine ML, Holmes JL, Streat S, Burrows C R (2007) Euthanasia: a word no longer to be used or abused. Intensive Care Med 33: 549-550.

3. Truog R (2006) End-of-life care: Is euthanasia the answer? Intensive Care Med 32: 6-8.

4. Solsona JF, Campos JM, Vazquez A, Diaz Y (2006) Comment on "End-of life care: Is euthanasia the answer" by R. Truog. Intensive Care Med 32: 1661.

5. Del Nogal Saez F (2006) Opiates at the end of life in an emergency department in Spain: Euthanasia or good clinical practice? Intensive Care Med 32: 10861087.

6. Beauchamp TL and Davidson Al: The Definition of Euthanasia, in: S. Gorovitz et al (Eds.), MORAL PROBLEMS IN MEDICINE, Englewood Cliffs, NJ: Prentice Hall, 1983, p 447, citing Baruch Brody, Voluntary euthanasia and the law, in: Marvin Kohl (Ed.) BENEFICENT EUTHANASIA, N. Y., Prometheus Books, 1975, p 218. 
Citation: Pavlovic D, Spassov A, Lehmann C (2011) Euthanasia: In Defense of A Good, Ancient Word. J Clinic Res Bioeth 2:105. doi:10.4172/21559627.1000105

Page 5 of 5

7. Flow A (1969) The principle of euthanasia, in: Downing, A.B. (Ed.) EUTHANASIA AND THE RIGHT TO DEATH, Los Angeles, Nash Publishing pp 30-48.

8. Tuffs A (2003) Nazi's euthanasia files are made public. BMJ 327: 832.

9. Mitscherlich A, Mielke F (1960) Medizin ohne Menschlichkeit: Dokumente des Nürnberger Ärzteprozesses. Fischer Bucherei p. 183.

10. Tatlisumak T (2006) Euthanasia in small animals, in Tatlisumak $T$ and Fisher M (Eds.): Handbook of Experimental Neurology: Methods and Techniques in Animal Research, Cambridge University Press.

11. AVMA GUIDELINES ON EUTHANASIA (2007) American veterinary medical association.

12. CODE OF PRACTICE FOR THE HUMANE KILLING OF ANIMALS UNDER SCHEDULE 1 TO THE ANIMALS (SCIENTIFIC PROCEDURES) ACT 1986 (issued under Section 21) Presented pursuant to Act Eliz. II 1986 c. 14 Section 21 (Animals (Scientific Procedures) Act 1986) Ordered by The House of Commons, 1997. http://www.homeoffice.gov.uk/docs/hc193.html, accessed August 4, 2008.

13. Close B, Banister K, Baumans V, Bernoth E-M, Bromage N, et al. (1996) Recommendations for euthanasia of experimental animals. Lab Anim, Part 1 30: 293-316 and Part 2 (1997) 31: 1-32.

14. Schultz TR, Wells D, Sarada M (1980) Development of the ability to distinguish intended actions from mistakes, reflexes, and passive movements. Br J Soc Clin Psychol 19: 301-310.
15. Aristotle: Problems 954b35-955a28; NICOMACHEAN ETHICS, $1138 a 6$ and further, and 1116a12. Also, at 1166b13, he maintains that the bad man would be also bad toward himself.

16. Arrian: ANABASIS OF ALEXANDER, 7.18.

17. Diodorus Siculus: LIBRARY OF HISTORY, 17.107

18. Plutarch, LIFE OF ALEXANDER, 73.3-5.

19. Quintus Curtius Rufus: THE HISTORY OF ALEXANDER THE GREAT 10 1-end, supplement, by the translator Jean Freinshemius, in the French-Latin edition, Lille 1712.

20. Stephanus H (1572) (Estienne, Henri.) THESAURUS GRAECAE LINGUAE. Geneva, book III.

21. Cicero: LETTERS TO ATICUS $(16,7,3)$.

22. Suetonius: VITA IMPERATORUM (August, 99).

23. Pavlovic D, Divac S (2005) Ethics of concerns and life cessation decisions: when emotions are all what remains, EUBIOS JOURNAL OF ASIAN AND INTERNATIONAL BIOETHICS (EJAIB). 15: 178-182.

24. Rorty RM (1992) Twenty-five years after, in Rorty R (Ed.): THE LINGUISTIC TURN 371-374. 